\title{
User Experience with Mobile Applications for Museums and Exhibition Spaces
}

\author{
Álvaro Sanchis ${ }^{1}$, Nuria Rodríguez ${ }^{2}$, David Heras ${ }^{3}$, Melani Lleonart ${ }^{4}$ \\ 1 \\ Universitat Politècnica de València, Departamento de Pintura \\ \{alsangan@pin.upv.es\} \\ 2 \\ Universitat Politècnica de València, Departamento de Pintura \\ \{nurodca@pin.upv.es\} \\ 3 \\ Universitat Politècnica de València, Departamento de Dibujo \\ \{dherase@dib.upv.es\} \\ ${ }^{4}$ Universitat Politècnica de València, Departamento de Pintura \\ \{mellgar@upv.es\}
}

\begin{abstract}
In this communication, we will analyse the use of resources that are useful in conceptualising museum apps, due to their interesting potential to improve the significance of the visit. Storytelling, gamification, and the inclusion of current technologies such as augmented reality and virtual reality will be determinant for the projection of stimulating, informative spaces. They will contribute to improve the didactic discourse, and the comprehension of complex concepts could be improved. To do so, the combination of the physical layout of the exhibition with overlapping digital layers of information mobile device-based would be essential.

Finally, we will analyse the case of the Ana Juan exhibition, Dibujando al otro lado (Drawing on the Other Side), produced by the Unit Experimental team. This exhibition combines the use of traditional exhibition resources with mobile devices, through a specific app. With it, visitors could experiment an augmented visit, in which different types of digital content were applied. Some of the resources used where game-based, storytelling, augmented reality and virtual reality. The initial design, production and results analysis of this exhibition will be very useful to validate the potential of mobile technology in the creation of significant informative experiences both in museums and other type of settings.
\end{abstract}

Keywords: museography / interactivity / user experience 


\section{Introduction}

The presence of digital technology is one of the characteristic features of today's developed societies. The transformations this technology has made possible over the last decades have modified not only how we communicate, but also how we produce and consume information. Faced with this new paradigm that allows us to share content almost immediately and from anywhere, museums and exhibition centres, anchored to a physical space, are at a distinct disadvantage in spreading the culture and knowledge they contain compared with other hugely popular entertainment media (Rico, 2002, p.43). Given this situation, museums have frequently resorted to technology to improve their offer and win over their target audience, adapting it to the media and languages of modern-day visitors.

One of the main functions of the modern museum is to facilitate the understanding of concepts through the act of exhibition and therefore it frequently uses didactic resources to communicate with its visitors. It is at this point that digital technology plays a prominent role, helping to shape what we know as the 'museography of experience', and enhancing its didactic capacity. These types of resource, used at first in educational museums and later popularized in other areas, became widespread during the last decades of the 20th century, continuously making use of the latest technological innovations. Good examples are the use of typical mass media devices, such as TV or radio (Tallon, 2009). The adaptation of interactivity through the personal computer or the use of the internet to generate new channels of communication were likewise fundamental. (Alcalá, Fernández and Rico, 2009, p. 20)

During these decades, interactive museography took advantage of the characteristics of each medium to reach out to the public, offering novel and attractive experiences with varying degrees of success. The arrival of smart mobile devices, however, is completely revolutionizing the way museums communicate with their visitors, resulting in a definitive rupture with regard to previously used technologies and opening up a new horizon of possibilities yet to be discovered.

\section{Museological interactivity in the era of the smartphone}

The launch of the first smartphone was a wakeup call in the production of digital assets for museums. Several features of these devices were especially relevant and facilitated their mass implementation, most notably their interactive touchscreens, their ability to reproduce multimedia content (audio, video, etc.) and the functionalities of internet connectivity and GPS tracking. For the first time, museums could publish content for consumption on the visitors' own devices, regardless of their location, giving rise to what we know as 'nomadic museography' (Hernández, Martínez and Rojo, 2010, p. 590). 

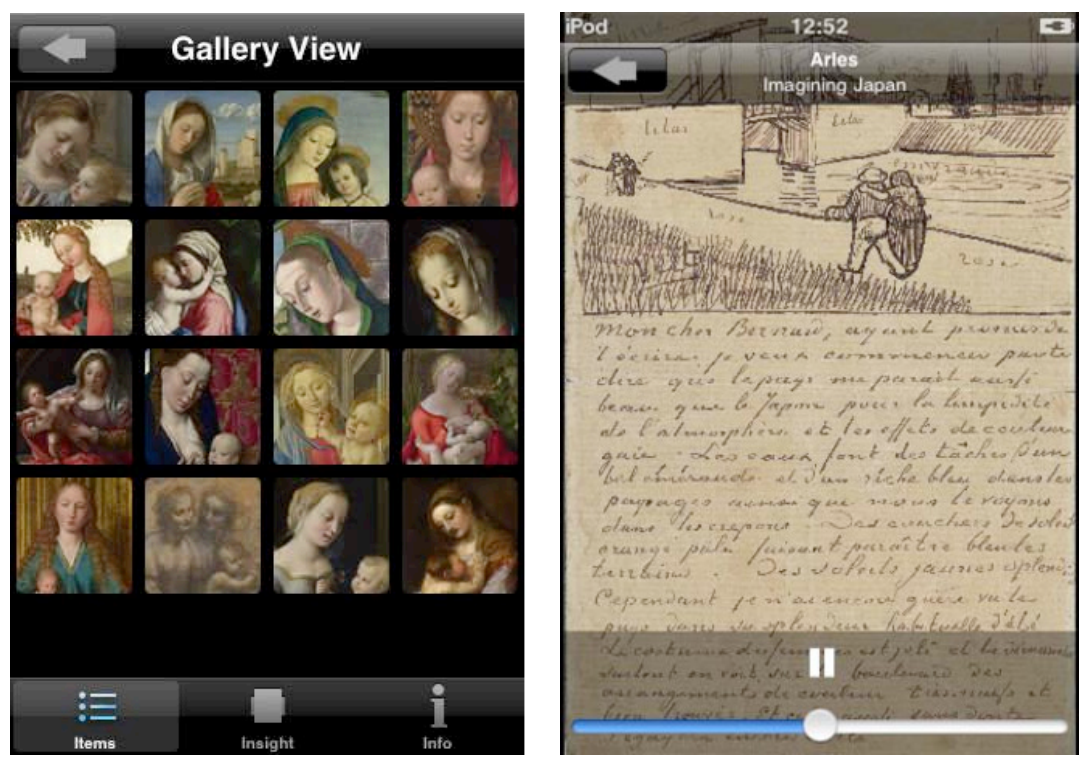

Fig. 1 and 2. Pioneer applications published by museums. From left to right, Love Art (2009) published by the National Gallery in London, and the Yours, Vincent application (2009) produced by the Van Gogh Museum in Amsterdam.

At present, ten years after the launch of the first smartphone, we have a clearly consolidated medium of great interest for museums. According to the survey published by the AXIELL ${ }^{1}$ company, $93 \%$ of the museums surveyed were interested in or already producing some type of interactive digital content in the next year. The experience of our work team confirms that museum institutions show a clear interest in the field of interactivity, but are not familiar with the most appropriate resources and possibilities currently available in order to connect with their different target groups. What resources can museums use to attract visitors? What are the determining factors in making the experience of visiting a museum truly meaningful? As a starting point, we have taken areas of study such as museography and user experience design to detect aspects that are more effective in the creation of meaningful interactive experiences, the fundamental aim of any cultural institution today.

It is essential to understand that the approach, means and strategies used to present an exhibition will result in either a humdrum non-event or a truly meaningful experience for our visitors. Therefore, through the area of user experience design,

\footnotetext{
${ }^{1}$ The study carried out by AXIELL in 2016 surveyed more than 1,000 exhibiting institutions around the world, obtaining information on their use and perception of technology as a museological tool. The study can be found at http://alm.axiell.com/digital-transformationmuseum-industry/ [Consulted 17/10/17]
} 
we can discern some key factors that can guide us on how to detect relevant aspects in the approach to digital museum assets. First, we must understand the dimensions that make for a rewarding experience, which according to Morville (2004) have six distinct characteristics, namely that they are useful, desirable, accessible, credible, locatable and usable. The presence of all of the above will result in a truly rewarding experience.

Taking these dimensions as a starting point, and based on our own experience as consultants and producers of interactive experiences, we have identified three key resources that improve the dimensions proposed by Morville, thus facilitating the creation of positive interactive experiences for museum visitors: first, the use of novel technologies such as augmented/virtual reality, together with key strategies such as storytelling and ludification. We will now break each one of them down in order to analyse their applications in specific projects.

\subsection{Use of new technology: augmented and virtual reality}

Augmented reality and virtual reality are currently two of the most important resources in the interactive audiovisual sector. There are several reasons for this trend. First, as Peter Morville (2004) points out, one of the key aspects in improving a positive user experience is desirability, which is clearly enhanced by users' curiosity and their willingness to try out new products and experiences.

Augmented reality is especially useful as a museological tool because of its ability to amplify the content on display at exhibitions. Thus, the exhibition spaces can be complemented by overlapping information of interest with the traditional exhibition supports in an attractive, playful and effective way. A good example is the interactive sketchbooks developed by the Unit Experimental team in the exhibition Think With Your Hands. Isidro Ferrer \& Pep Carrió sketchbooks (2013), where visitors were allowed to virtually 'browse' the sketchbooks presented in the exhibition inside display cases or printed on panels (fig. 3). It is also possible to use the communicative media of the exhibition (posters, brochures, information sheets) as images that are detectable by the application, thus bringing the user experience outside the halls and allowing a greater dissemination of the digital content that has been developed. 


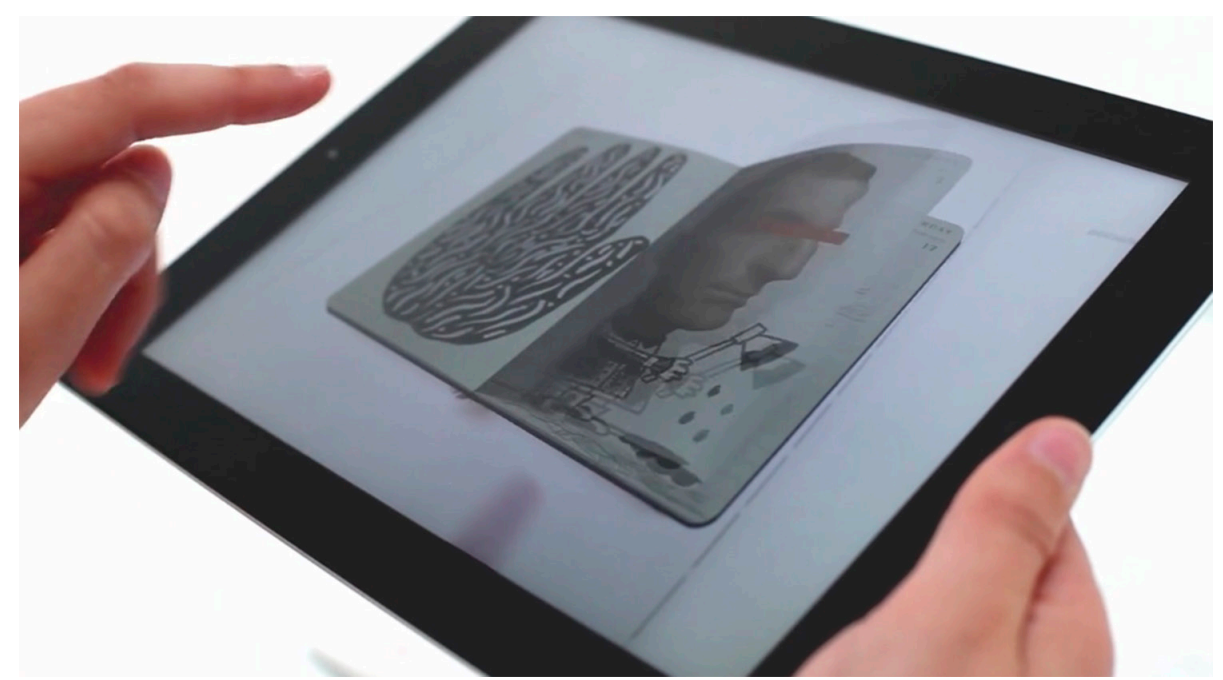

Fig. 3. Interactive sketchbook in the exhibition Think With Your Hands. Isidro Ferrer \& Pep Carrió sketchbooks (2013). Image: Unit Experimental

Similarly, in the EFE'75. History of the First Spanish News Agency (2014), Unit Experimental developed a specific application that used augmented reality to offer additional information about photos, events and key documents, providing audiovisual resources, animations and 3D resources that amplified the visit (fig. 4).

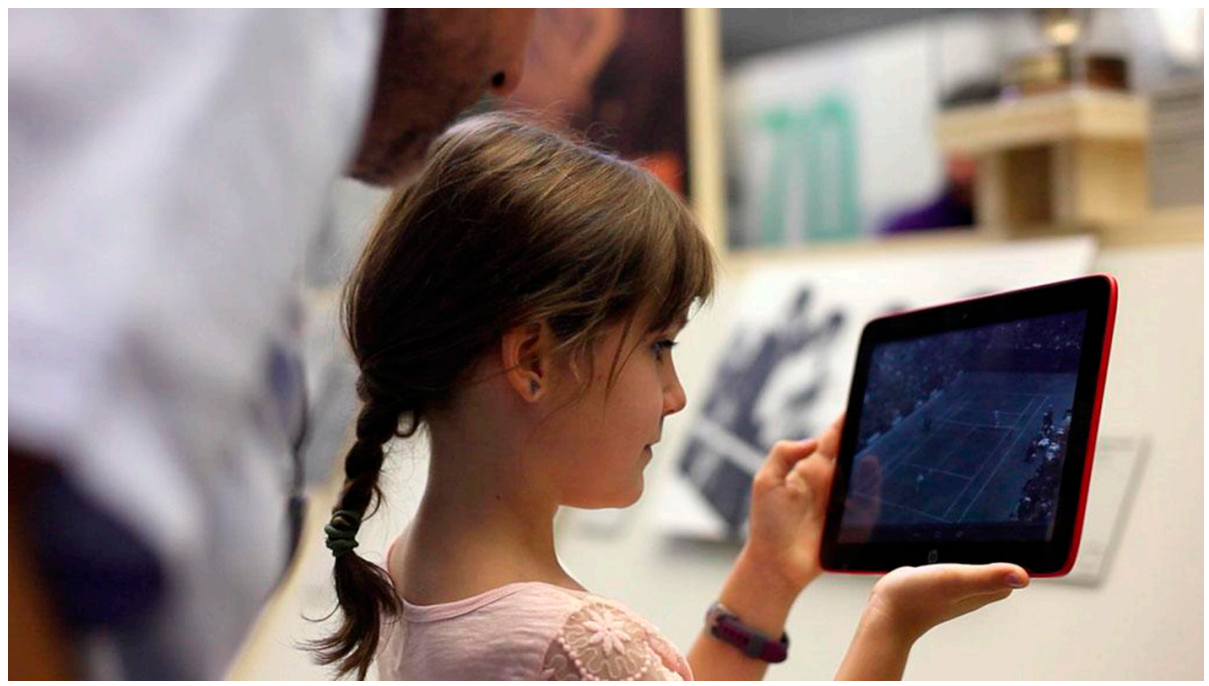

Fig. 4. EFE $75^{\prime}$ application, showing audiovisual content from a news clip. Image: Unit Experimental. 
In parallel, virtual reality is the next step in the simulation of digital experiences, as it offers the total abstraction of reality, immersing the viewer in a completely new environment. It is therefore a high impact resource since it enables the visitor to be transported to ages, situations or realities impossible to experience through other simulation methods. At present, virtual reality arouses special interest within the museological panorama due to the curiosity and intensity that its results provoke in visitors. In this vein, the Dalí Museum in St. Petersburg has presented the Dreams of Dalí VR experience (fig. 5), an interaction based on virtual reality that allows the visitor to enter into a dreamlike universe based on Dalís Archaeological Remini-scence of Millets Angelus (1935), allowing the viewer to discover details about the artist's creative process.

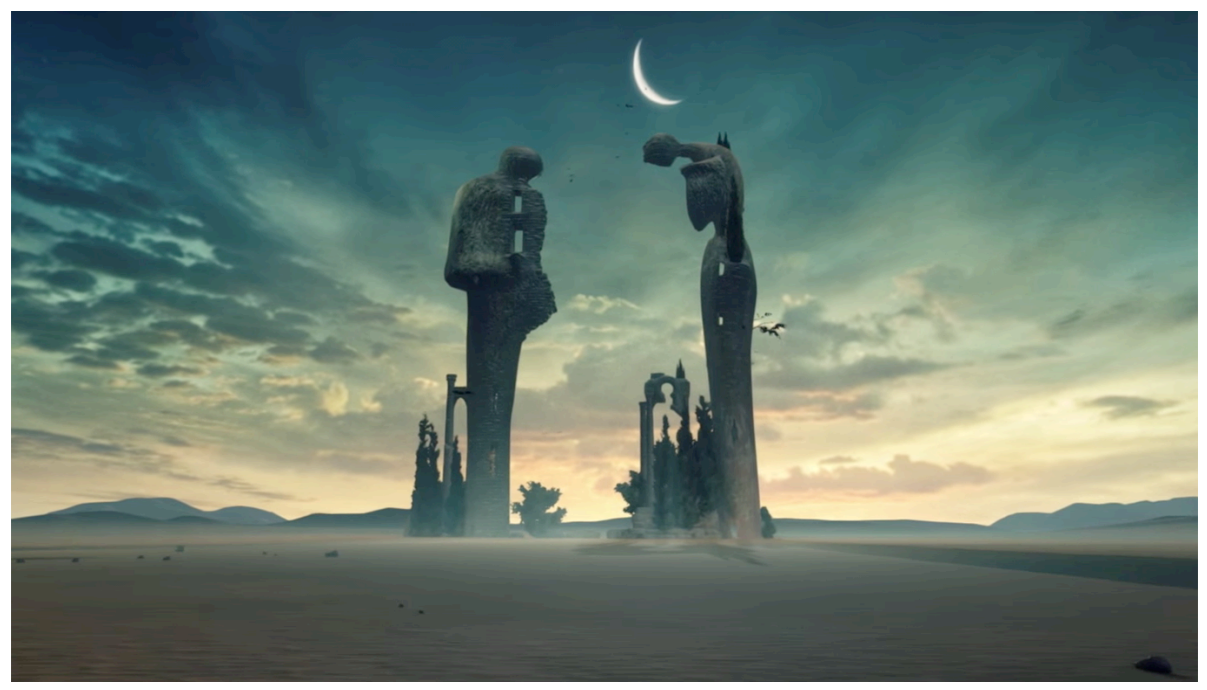

Fig. 5. Dreams of Dalí VR (2017) application. Image: Dali Museum, St. Petersburg

\subsection{Storytelling}

As part of our analysis of the most useful tendencies in the creation of digital museum experiences, it is clear that storytelling is currently one of the most widespread tools, both in the exhibition narrative and the approach to digital experiences. This resource uses the evident capacity and scope of stories as a didactic and communicative tool. Since ancestral times, stories have transcended as a primitive form of communication, given that the use of stories and legends has for centuries been the mode of transmission of culture and traditions (Ruthledge, 2011), with museums later becoming excellent agents for their transmission. The digital field has facilitated the inclusion of these stories in expository approaches, especially mobile devices, due to their multimedia and interactive possibilities. A good example is the Traces Olion application (2017), produced by the Cardiff National Museum, which allows a physical visit to the museum to be combined with a narrative that 
involves the spectator, making them a participant in an adventure where they will learn about the lifestyle of the main inhabitants of the society of this city at the beginning of the century.
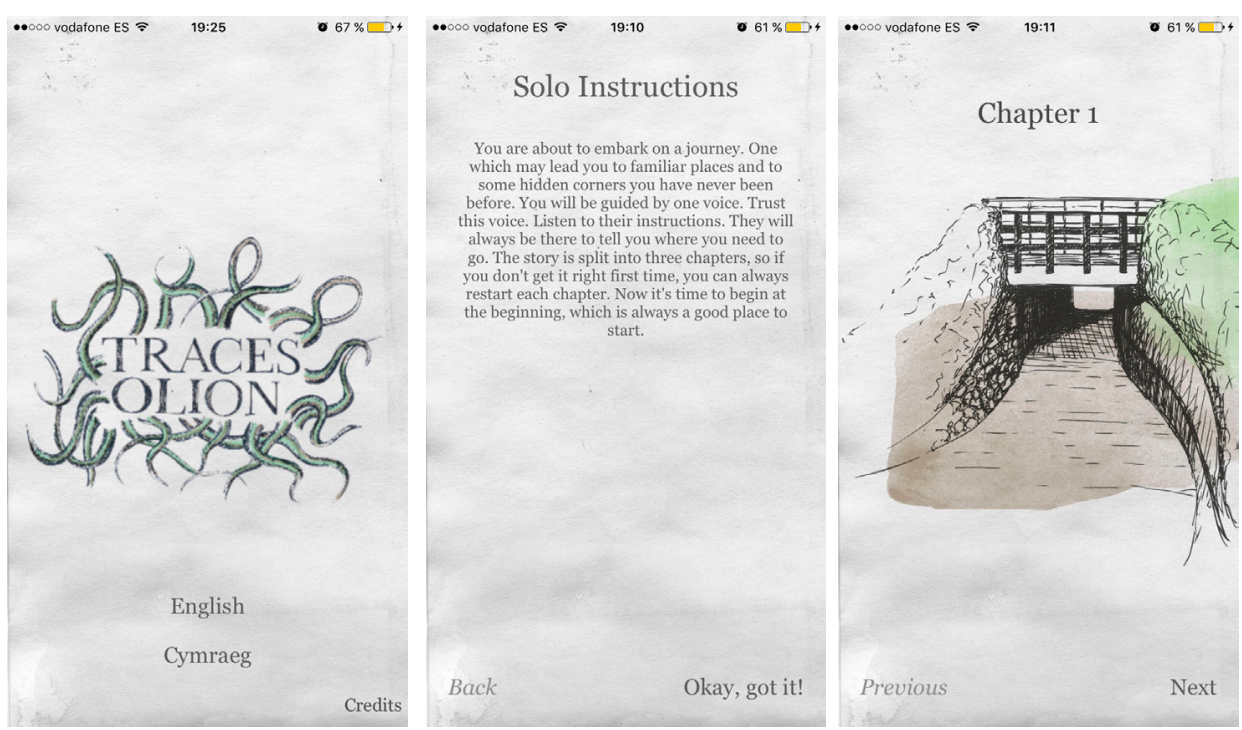

Fig. 6, 7 and 8. Several screenshots from the Traces Olion application (2017). Image: Apple Appstore

\subsection{Gamification}

Gamification has come to the fore in recent years as one of the most interesting resources in interactive museography. This trend stems from the use of resources from the world of gaming applied to environments of all kinds. As Jesse Schell says: "gamification is taking things that are not games and trying to change them so that they are experienced as such."

Firstly, the principles of gamification are consistent with those that form the basis of human learning, which during infancy is grounded fundamentally in play. In adulthood, play is related with fun activities, which are stress-free and entertaining, and therefore the gamification of certain museum-related environments is related to leisure and entertainment as an agent that constructs knowledge (Hernández, Martínez and Rojo, 2010). Secondly, those age groups who were born from the 1980s onwards display an obvious empathy with digital entertainment and video games, as they currently constitute a common medium for their entertainment and culture (Lippenholtz, 2014). For this reason, the use of dynamics close to these spheres will have a positive effect on capturing the attention of museum visitors, generating learning dynamics and an in-depth exploration of complex subjects through action or "doing" (Green and Hannon, 2007). Hence, it is fundamental that the gamified experiences that museums present meet certain criteria, such as: 
- Maintaining a balance between difficulty and user skill;

- $\quad$ Clearly setting out the objectives and tasks to be performed;

- $\quad$ Generating a seamless game experience without obstacles or interferences;

- $\quad$ Combining game content with didactic information in a balanced way;

A good example of how to approach this type of dynamic can be found in the MicroRangers project developed by the American Museum of National History in 2016. In it, visitors are invited to experience an adventure in which, using augmented reality on a card given to each visitor participating in the activity, they take part and help digital characters. The challenges set include ones that involve observing the museum environment to "hunt" for specific specimens and solve puzzles.

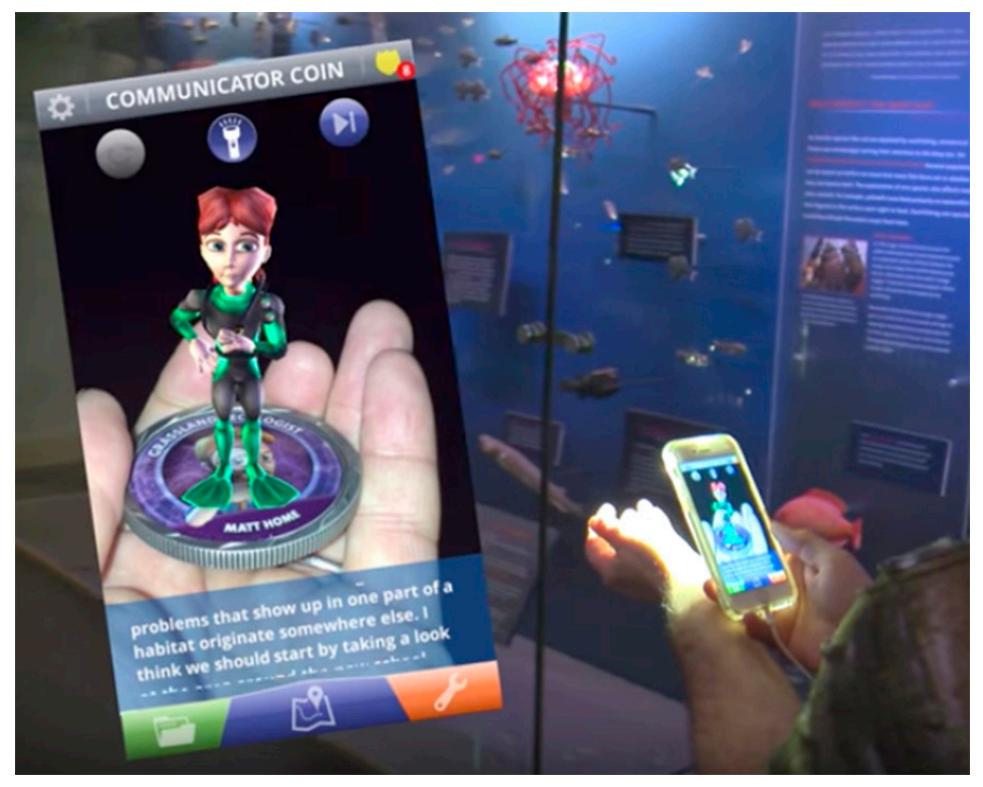

Fig. 9. A virtual character giving instructions in the gamified MicroRangers activity in the American Museum of National History.

At the same time, it is important to stress that due to the different types of visitor a museum may receive, it is crucial to avoid what we call "game-tatorship", that is, to avoid forcing all visitors to participate in the experience, as there may be people who prefer to visit the exhibition without the extra support that an approach of this kind offers. 


\section{Ana Juan, Drawing on the other side: a transmedia exhibition}

The research process related to resources that are useful in the digital interactive activities described in this article are complemented with their practical application in the production of an exhibition. In this project, the Unit Experimental team combine the various different resources analysed with the aim of providing an attractive and meaningful exhibition that allows us to corroborate the intuitions which gave rise to our research. The result was the interactive exhibition Ana Juan, Drawing on the other side, presented for the first time at the Josep Renau Room of the Faculty of Fine Arts (Polytechnic University of Valencia, 2015) and subsequently at the $A B C$ Museum of Drawing and Illustration (Madrid, 2017).

\section{Aims of the exhibition}

The basic approach was aimed at creating an expository montage that would enable the viewer to enjoy two works created by the illustrator Ana Juan: $A$ turn of the screw and Snow White. As well as the physical exposition, we set out to make an application for mobile phones and tablets that shares the same title as the exhibit. In this app, a clear sub-division was created between information integrated in the interface (which organized elements via menus and sub-sections) together with content displayed by means of augmented and virtual reality in the room. The selection of this technology as a tool to organize the navigation also allowed us to integrate the resources we have commented on above, converting the display into a transmedia experience that combined a solid museographic approach with digital support based on story-telling and gamification.

We can summarize as follows the types of interaction that were included and tested in this exhibition:

\begin{tabular}{|l|l|}
\hline Classification by type & $\begin{array}{l}\text { Number } \\
\text { present in } \\
\text { the room }\end{array}$ \\
\hline Interactive large format posters with gamification (challenge to be solved) & 4 \\
\hline Video footage showing Ana Juan's creative process & 17 \\
\hline 3D characters to be viewed in augmented reality & 11 \\
\hline Augmented reality of the Hawthorn mansion & 1 \\
\hline Visit to the Hawthorn mansion in virtual reality & 1 \\
\hline $\begin{array}{l}\text { Virtual interactive theatre, combining a physical scenography with virtual } \\
\text { elements. }\end{array}$ & 1 \\
\hline $\begin{array}{l}\text { Tablets for playing Chapter I of the videogame Erthaland. Snow White's mystery } \\
\text { tale developed by Unit Experimental based on the work of Ana Juan }\end{array}$ & 1 \\
\hline
\end{tabular}




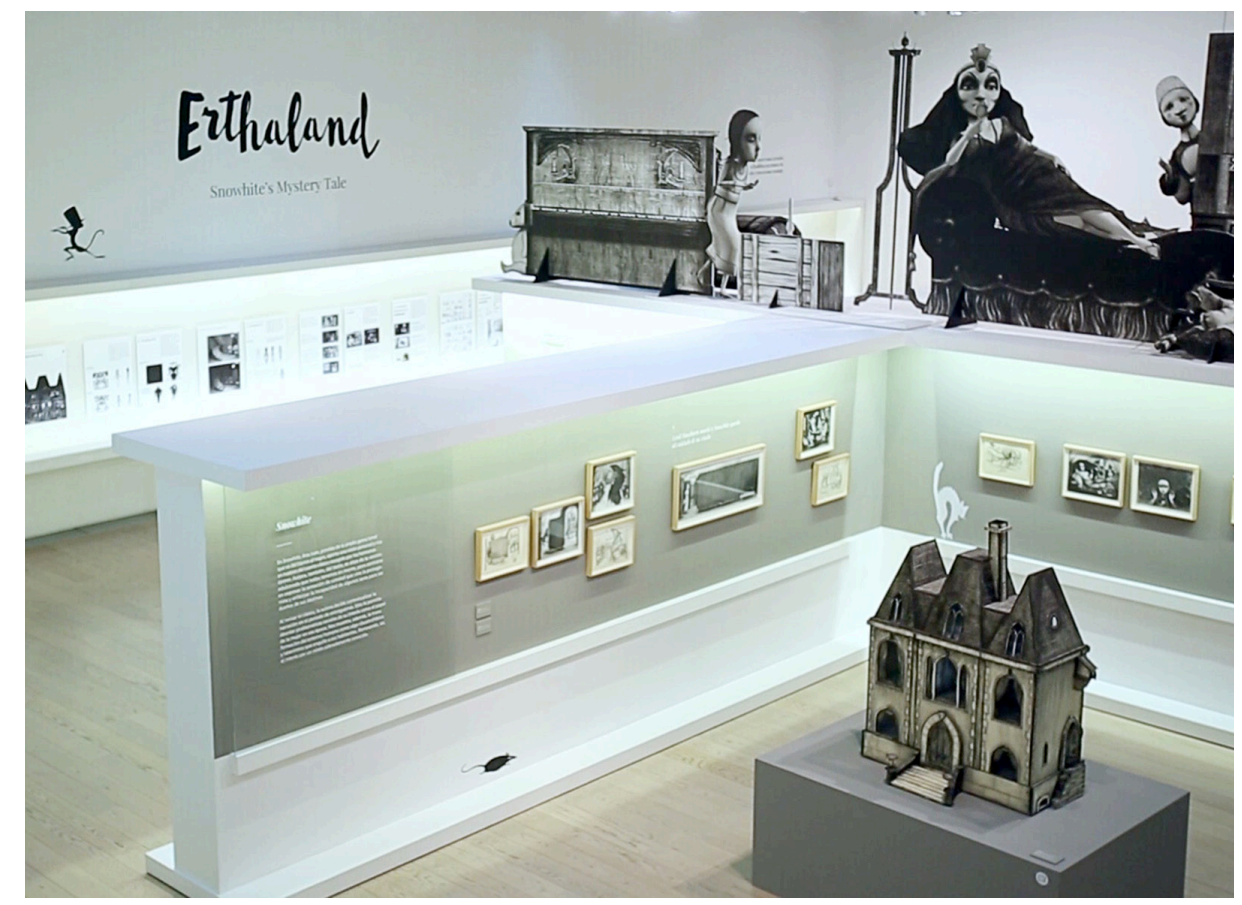

Fig. 10. View of the exhibition Ana Juan, Drawing on the other side (2017) at the ABC Museum of Drawing and Illustration. Image: Unit Experimental.

\section{A gamified narrative experience}

As we have said, the fundamental objective of the approach was to use resources that are typical of story-telling in tandem with gamification to turn the exhibition into a board game where the visitor can overcome the initial challenge and finally win a reward. The visitors who entered the room encountered instructions (signposted on one of the walls using vinyl posters) in which they were encouraged to participate in the activity (fig.11). Thus, in a clear and simple way, the user is invited to play an active role in the narration and be a participant as the heroine flees in this new twist on the classic tale as revised by Ana Juan.

The gameplay dynamic based on augmented reality called for a specific design process to allow for an appropriate and accessible playability. In our case, by focusing with the tablet on any of the four interactive vinyl posters positioned in the room, the visitor was shown an interactive scene that included both the Ana Juan characters and various items of furniture and interactive elements that can be used to solve the puzzle. These mini-challenges called for dynamics combining objects, logic games and memory games. 

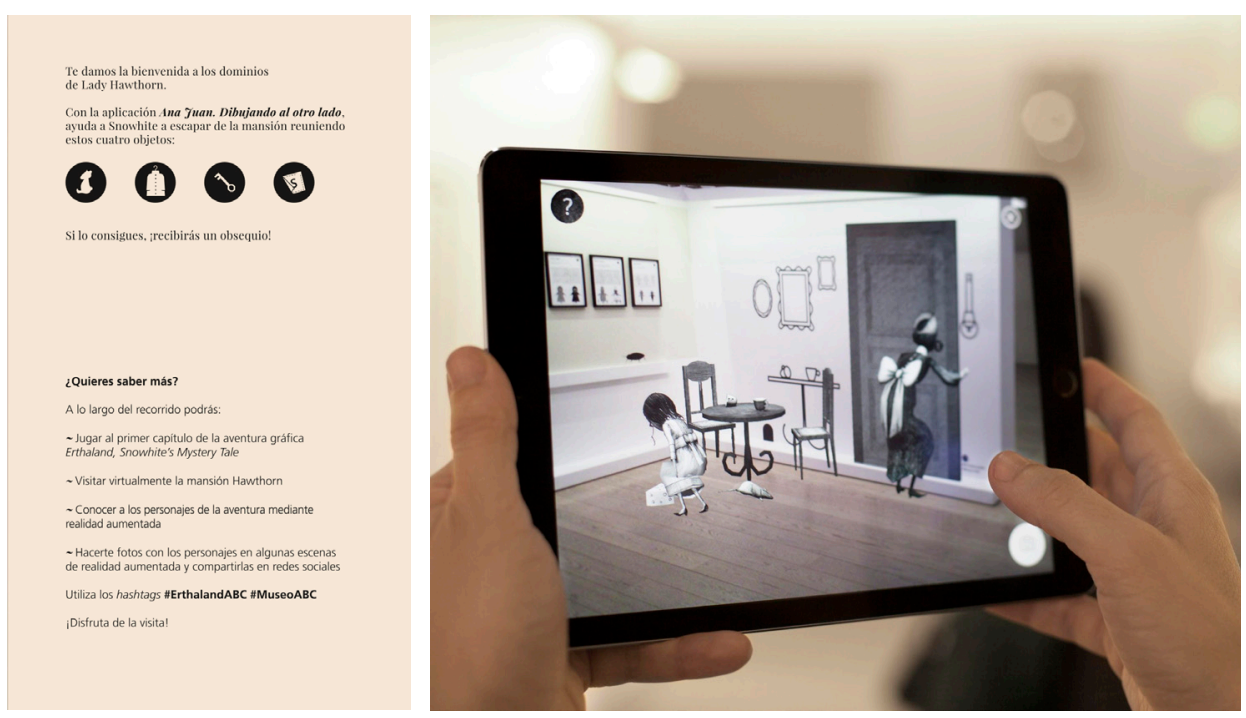

Fig. 11. Poster positioned at the entrance to the exhibition with instructions on the ludic experience. Image: Unit Experimental.

Fig. 12. An interactive vinyl poster that displays a logical challenge by means of augmented reality. Image: Unit Experimental.

To effectively tell the user the objective to be achieved in each interaction, we developed a train of thought for the main character, Snow White, so that through the classic thought bubbles of comics one knows at all times what the character is thinking and, therefore, what objective should be achieved. Visitors could experiment, move and combine the various objects with the characters to solve the four riddles and obtain the objects required to overcome the challenge posed in the room.

Overcoming a challenge is an intrinsic part of the experience of participating in any game. Consequently, we designed a reward that would add value to the experience and fit in with the possibilities and functioning of the museum where the exhibition was staged. Ruling out traditional media such as the room fact sheet or postcards, we designed a new medium in the form of a cut-out, laid out on an A3-size sheet of paper. When cut out and assembled correctly, it made a small-scale replica of the Hawthorn mansion displayed in the exhibition. Furthermore, we were able to add digital interactivity to this cut-out item, enabling the visitors to take home their interactive experience of the room and enjoy the augmented reality experience outside the museum and, what is more, to share it with other potential visitors. 


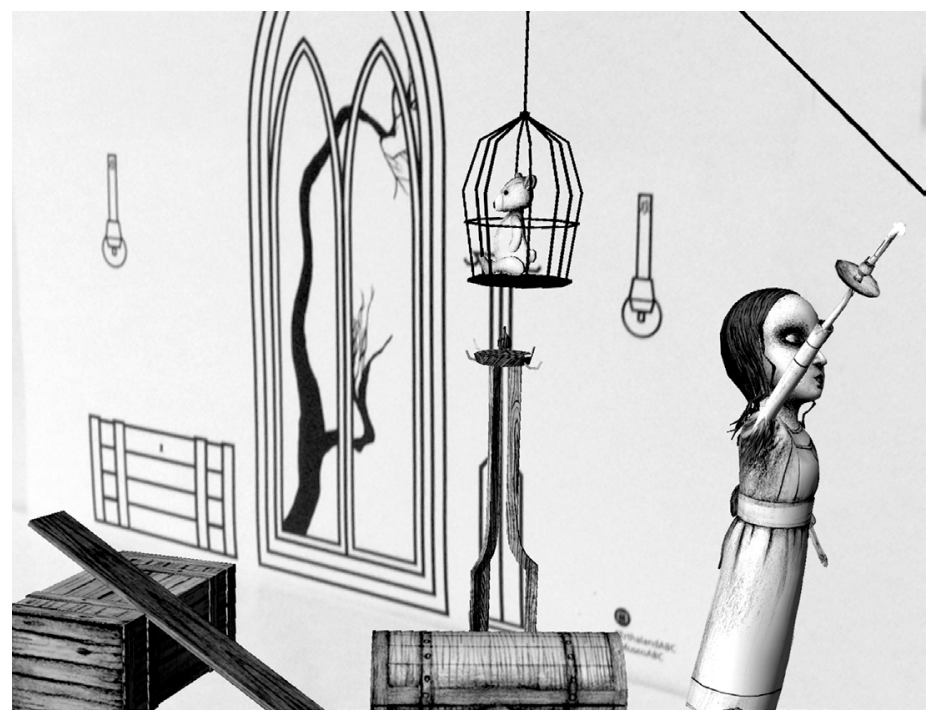

Fig. 13. Snow White solving one of the puzzles in the game experience. Image: Unit Experimental

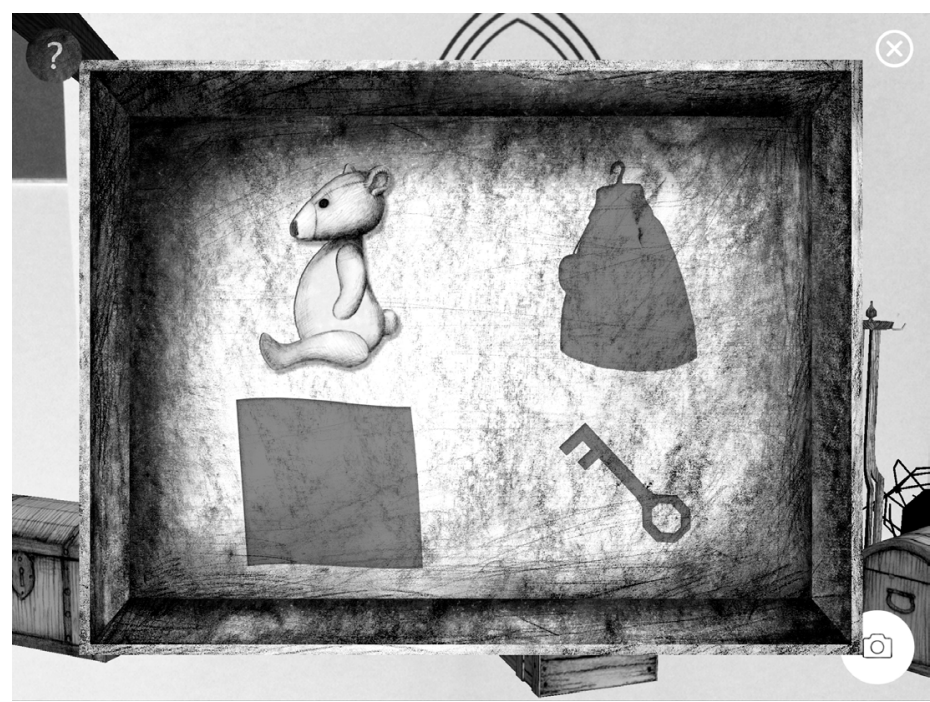

Fig. 14. Shopping list showing the four objects required to overcome the challenge. Image: Unit Experimental 


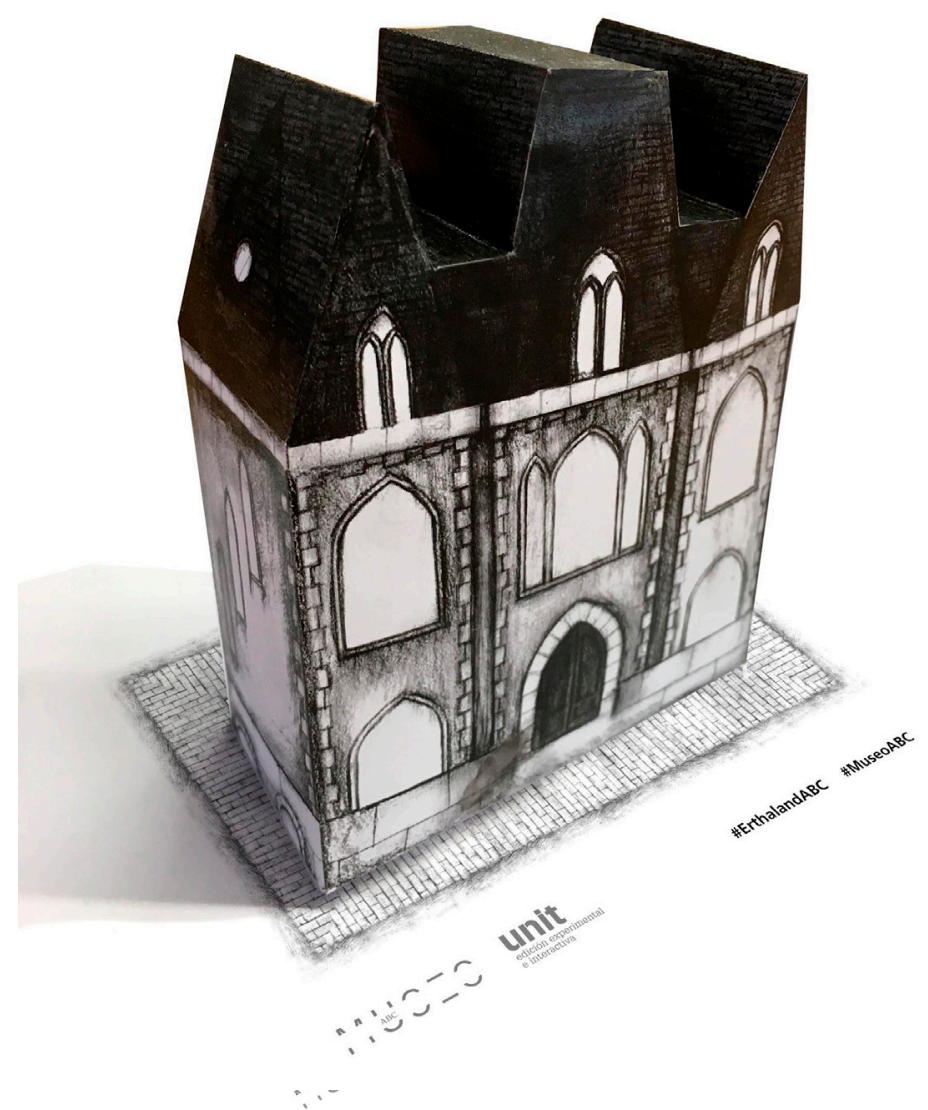

Fig. 15. Photograph showing the cut-out mansion when assembled.

\subsection{Reception and outcome of the exhibition}

Looking at the statistics obtained by the analysis integrated in the application, the interaction types that were most used in the exhibition were:

1. Scenes of the game challenge in augmented reality: $51.2 \%$

2. Augmented reality of the Hawthorn mansion: $13.9 \%$

3. Augmented reality of the cut-out house: $9.5 \%$

4. Interactive virtual theatre: $9.13 \%$

5. Vídeos on the work of Ana Juan: $8.8 \%$

6. 3D characters to be viewed in augmented reality: $5.9 \%$

7. Augmented reality applied to the promotional flyer for the room: $1.7 \%$

In total, 67,231 content activations were recorded (one each time the application detected a target or digital content), the percentages being distributed as follows: 
resenting the total number of people who overcame the interactive challenge in the room. It should be borne in mind that the user could choose to enjoy the full interactivity and participate in the challenge, or enjoy the exhibition and digital content in augmented reality and virtual without the gamified part. Some visitors tour the exhibition by viewing the works and attending to the interactive documentary resources, such as interviews, information about the work process character animations.

The following graphs show the numbers of visitors, which amounted to a daily average of 298 and whose weekly audience did not fall from 1,000 people in any of the three months in which it could be visited, exceeding 1,500 visitors most months. The $A B C$ Museum of Drawing and Illustration has an average of 160 attendees per day, a statistic that underlines the clear success of our interactive feature. Moreover, in surveys and interviews conducted with visitors in the museum itself, we could see that most of them ranked the works of the illustrator Ana Juan above interactivity, thus demonstrating that technology does not exclude the importance of the work itself, but helps to enhance its message and to focus the viewer's attention.

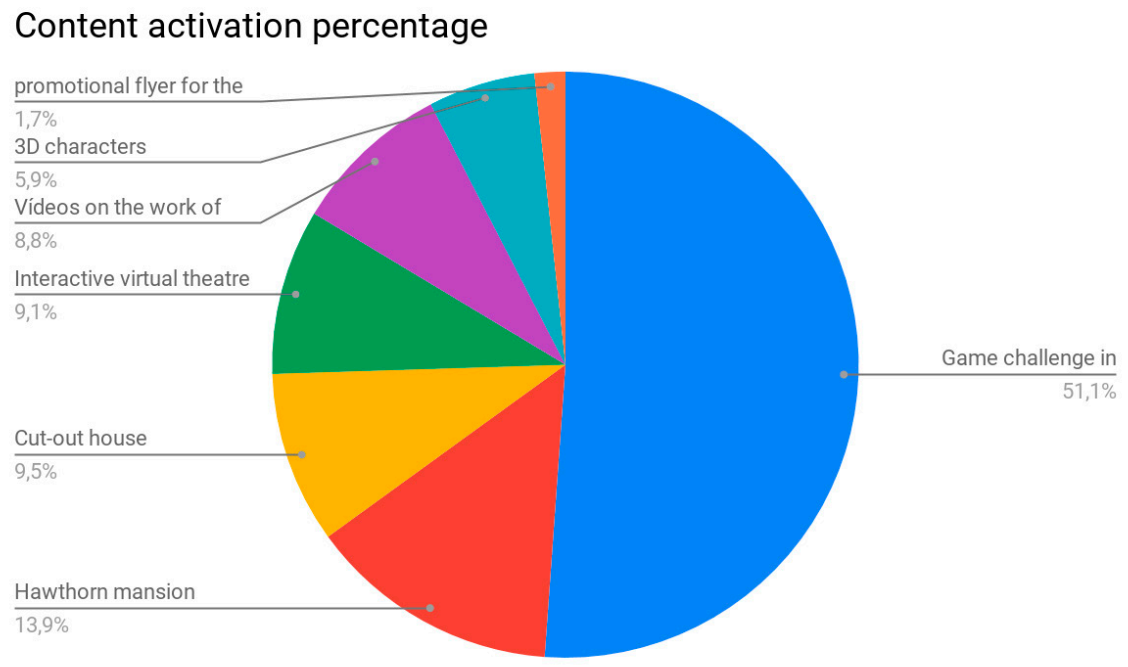

Fig. 16. Graph of activation percentages of augmented reality content 


\section{Asistencia semanal}

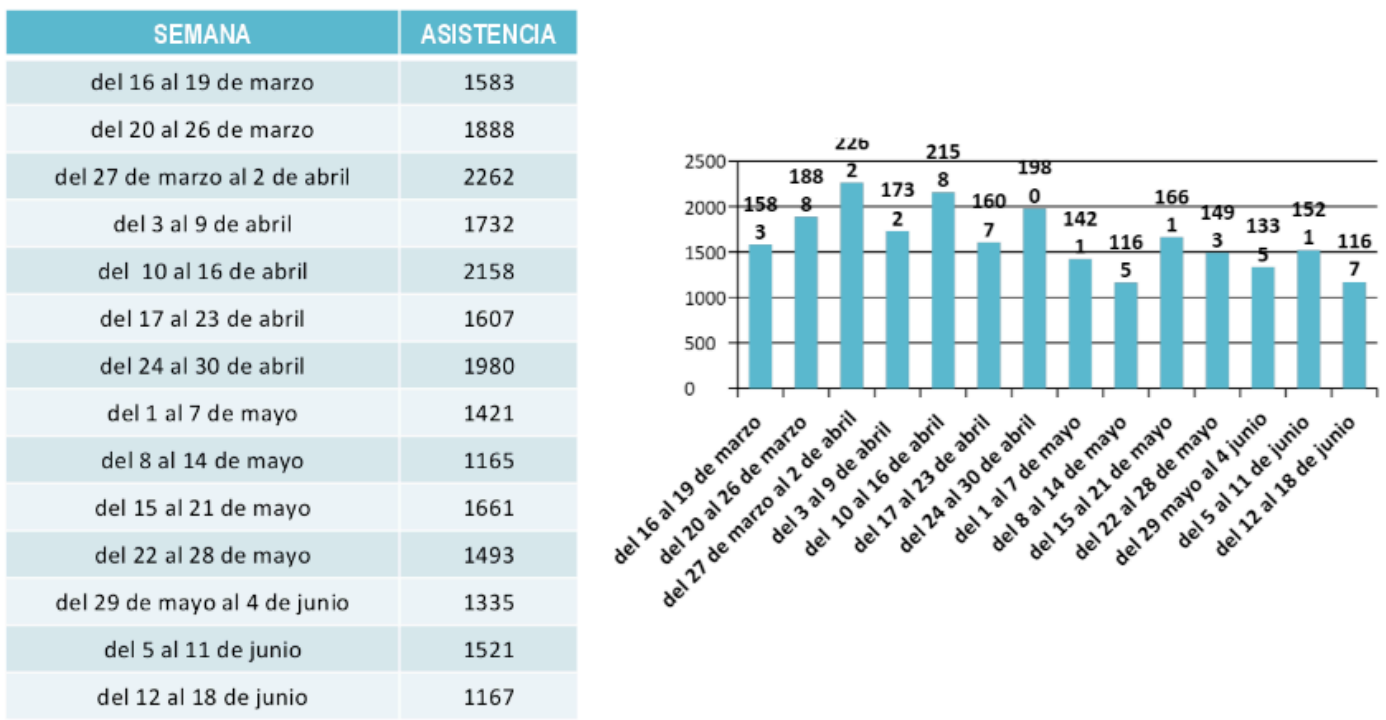

Fig. 17. Graphs showing weekly attendance at the exhibition. Source: ABC Museum

\section{Conclusions}

Having marked out the current strategies of greatest interest in the digital museographic field, and having put them into practice in a specific project such as the interactive exhibition Ana Juan, Drawing on the other side, we can conclude that:

- $\quad$ The relationship between museography and technology is a field of study of great importance due to its usefulness in the transmission of complex content and its presence in visitors' everyday lives.

- The vast number of digital applications produced by museums require specific approaches designed to attract the public using surprising and stimulating interactions.

- $\quad$ Augmented reality and virtual reality are useful tools for adding meaning to the experience of visiting a museum, especially when they are grounded on a teaching and learning narrative.

- $\quad$ Augmented reality is a strategy that offers high accessibility, which allows content to be enjoyed by visitor segments of very diverse ages.

- $\quad$ Storytelling and gamification have been shown to be valuable tools within contemporary museography, proving key to the connection with certain types of audience, and whose potential has not been explored as deeply as it should. 
- Analysing the results obtained from the statistics of the exhibition Ana Juan, Drawing on the other side, we conclude that within the possibilities of augmented reality the success of game experience is clear, thus paving a clear way for exploration of the achievement of meaningful experiences and the transmission of concepts in a playful and educational way.

\section{References}

1. Alcalá, J., Fernández, L., y Rico, J. (2009). ¿Cómo se cuelga un cuadro virtual? Las exposiciones en la era digital. Gijón, Spain: Ediciones Trea.

2. Green, H., and Hannon, C. (2007). Their space. Education for a digital generation. London, UK: Demos.

3. Hernández, F. (2009). Interactividad didáctica y museos. Enseñanza de las ciencias sociales, 8, 91-96.

4. Hernández, F., Martínez, T., y Rojo, M. (2010). Los límites de la interactividad. In Santacana J., and Martín C., Manual de museografía interactiva. Gijón, Spain: Ediciones Trea.

5. Lippenholtz, B. (2014). Gamificación en los museos (I). Documotion.com.ar [online resource] Retrieved from: http://documotion.com.ar/gamificacion-en-los-museos-i/ [Accessed: 15 December, 2015]

6. Morville, P. (2004). User Experience Design. Semanticstudios.com [online resource] Retrieved from: http://www.semanticstudios.com/user_experience_design/ [Accessed: 1 November, 2016]

7. Murphy, C. (2011). Why Games Work and the Science of Learning. Modsim World conference. Virginia Beach: Alion Science and Technology.

8. Rico, J. (2002). ¿'Por qué no vienen a los museos? Historia de un fracaso. Madrid, Spain: Sílex.

9. Schell, J. (2010). When games invade real life. Ted Talks [online resource] Retrieved from: http://www.ted.com/talks/jesse_schell_when_games_invade_real_life [Accessed: 12 December. 2015] 